Atmos. Chem. Phys., 10, 3189-3203, 2010

www.atmos-chem-phys.net/10/3189/2010/

(C) Author(s) 2010. This work is distributed under

the Creative Commons Attribution 3.0 License.

\title{
Consistency between parameterisations of aerosol hygroscopicity and CCN activity during the RHaMBLe discovery cruise
}

\author{
N. Good ${ }^{1, *}$, D. O. Topping ${ }^{1,2}$, J. D. Allan ${ }^{1,2}$, M. Flynn ${ }^{1}$, E. Fuentes ${ }^{1}$, M. Irwin ${ }^{1}$, P. I. Williams ${ }^{1,2}$, H. Coe ${ }^{1}$, and \\ G. McFiggans ${ }^{1}$ \\ ${ }^{1}$ Centre of Atmospheric Science, School of Earth Atmospheric and Environmental Sciences, \\ University of Manchester, Manchester, UK \\ ${ }^{2}$ National Centre for Atmospheric Sciences, University of Manchester, Manchester, UK \\ *now at: Laboratoire de Météorologie Physique, Blaise Pascal University, Clermont Ferrand, France
}

Received: 16 September 2009 - Published in Atmos. Chem. Phys. Discuss.: 26 October 2009

Revised: 15 March 2010 - Accepted: 23 March 2010 - Published: 1 April 2010

\begin{abstract}
Results from a measurement study performed in the Tropical Atlantic on board the RHaMBLe Discovery Cruise D319 are presented. Measurements of aerosol composition, hygroscopicity and $\mathrm{CCN}$ activity were used to test the ability of a single parameter model to describe water uptake in sub- and supersaturated conditions.

It was found that the magnitude and temporal variability of the sub-saturated water uptake could be well represented using the non-refractory composition to derive the model input for 2 periods when the large majority of the aerosol mass was non-refractory. As may be expected, when a significant fraction of the aerosol volume is refractory the sub-saturated water uptake is not well predicted by the non-refractory composition. When predicting the cloud activation potential from the composition and the hygroscopicity there is a consistent under-prediction of the $\mathrm{CCN}$ activity. The prediction of $\mathrm{CCN}$ activity from the sub-saturated water uptake gives a better prediction of the CCN activity than the composition when the non-refractory components are not fully representative of the aerosol composition.

Based on these observations it appears that a single parameter cannot always capture the behavior fully across the sub- and supersaturated regimes. Measurements made at relative humidities (RHs) up to $94 \%$ showed that the water activity appears satisfactorily represented by a single parameter
\end{abstract}

Correspondence to: G. McFiggans (g.mcfiggans@manchester.ac.uk) derived at $90 \% \mathrm{RH}$. It therefore appears that the change in the observed hygroscopicity take place between $94 \% \mathrm{RH}$ and the point of activation. This change may be due in part to a change solution non-ideality, surface tension effects or the presence of sparingly soluble compounds for example, but cannot be reconciled without measurements at higher RHs.

\section{Introduction}

Aerosol particles act as condensation nuclei in the moist atmosphere with the potential to take on water and form cloud droplets. Aerosol particles in the atmosphere absorb and desorb water vapour, with a net forcing effect on the earth's radiation budget owing to anthropogenic sources (Ramanathan et al., 1989; Harrison et al., 1990; Charlson et al., 1991, 1992; Tegen et al., 1996; Jacobson, 2001) via various mechanisms (Albrecht, 1989; Twomey, 1974). The magnitude of the radiative forcing as a result of aerosol effects contains the largest uncertainty in estimates of the anthropogenic affect on the earth's heat budget (Forster et al., 2007). A large part of the uncertainty results from aerosol effects which arise from imperfect knowledge and descriptions of the aerosol size distribution, composition and thermodynamics in climate models. In order to simply and accurately represent aerosol thermodynamics in large scale models the most important variables must be identified and described adequately.

Published by Copernicus Publications on behalf of the European Geosciences Union. 
Marine stratiform clouds play a major role in determining the earth's radiative flux, as they are extensive and their albedo is very large compared to that of the sea surface (Hartmann et al., 1992). The relatively large solar flux in the tropics will enhance the net radiative forcing of clouds in the region compared to more northerly latitudes. The sensitivity of the earth's radiative budget to low level cloud cover, means it is vital that their properties are well characterised (Klein and Hartmann, 1993).

The composition of a solution determines its water activity $\left(a_{\mathrm{w}}\right)$ and surface tension $\left(\sigma_{\mathrm{s}}\right)$. The relationship between a droplet's size and saturation ratio $(S)$ can be described in terms of these two properties using the Köhler Equation (Köhler, 1936; McFiggans et al., 2006). Numerous aerosol thermodynamic models have been developed, which describe the thermodynamics with varying levels of complexity (Topping et al., 2005a, and references therein). Representation of aerosol particle water uptake for atmospheric scale applications from cloud parcel to global scale models is limited by computational power and information, it is therefore necessary to make simplifying steps in its description. Any simplification needs to deliver results with the required accuracy for the application and will ideally be valid for a wide range of applications. Simplification of the Köhler equation requires separate expressions for the Raoult and Kelvin terms owing to their widely varying contributions as a function of $\mathrm{RH}$ and droplet size, the aim being to represent them in terms of as few variable parameters as is required. A number of authors have derived expressions for the Raoult terms using a minimal number of parameters, applying various simplifying assumptions about the physiochemical properties (e.g. Svenningsson et al., 1992; Weingartner et al., 1997; Swietlicki et al., 1999; Dick et al., 2000; Petters and Kreidenweis, 2007). In this study the $\kappa$-model (Petters and Kreidenweis, 2007) is used to describe the water uptake. The $\kappa$ parameterisation is used to examine the relationship between the measured subsaturated water uptake, the CCN activity and the water uptake predicted from the aerosol composition. The ability of single $\kappa$ values to represent water uptake during distinct meteorological periods in the tropical Atlantic Ocean was assessed.

The measurements reported here formed part of the Aerosol Characterisation and Modelling in the Marine Environment (ACMME) study (Allan et al., 2009) on the Reactive Halogens in the Marine Boundary Layer (RHaMBLe) Discovery Cruise D319 which took place between 19 May 2007 and 11 June 2007. The initial transit from Lisbon, Portugal to Mindelo, Cape Verde took 5 days. From Cape Verde the ship surveyed the region East of Cape Verde towards the Mauritanian coast before heading Northwards towards the Canary Islands. The region is of interest as a remote marine environment and as an area where primary sources of halogens may be active in the atmospheric chemistry impacting on aerosol formation and processing (Lee et al., 2010).

\section{Methods}

During the D319 cruise, online measurements of the aerosol hygroscopic growth, $\mathrm{CCN}$ activity and non-refractory composition were made. Their measurements were used to derive the hygroscopicity parameter $\kappa$ (Petters and Kreidenweis, 2007). The $\kappa$ values derived during the cruise were used within a simplified form of the Köhler equation to reconcile the aerosol composition, hygroscopic growth and $\mathrm{CCN}$ activity. The parameterisations of the online measurements were used to test the ability of single $\kappa$ values to represent the hygroscopicity during the cruise.

\subsection{Aerosol composition, number and size}

On-line measurements of the sub-micron non-refractory aerosol composition were made using a high resolution Aerosol Mass Spectrometer (AMS) (Canagaratna et al., 2007; DeCarlo et al., 2008). The AMS can determine the mass loadings of non-refractory inorganic (nitrate $-\mathrm{NO}_{3}$, sulphate $-\mathrm{SO}_{4}$ and ammonium $-\mathrm{NH}_{4}$ ) and organic (org) components in real time. The vaporisation technique employed by the AMS means that fragment ions from lower volatility molecules such as sodium chloride and mineral dust are not detected.

A four stage Compact Cascade Impactor (CCI) with cutoff diameters of $0.16,1.0,5.3$ and $9.9 \mu \mathrm{m}$ was used to collect daily samples for off-line analysis of the aerosol composition (Demokritou et al., 2004; Allan et al., 2009). The samples were analysed for inorganic aqueous ions using ion chromatography, UV-visible spectrophotometry and inductively coupled plasma atomic emission spectrometry.

A Differential Mobility Particle Sizer (DMPS) was used to measure the aerosol number size distribution between $10 \mathrm{~nm}$ and $700 \mathrm{~nm}$ (Williams et al., 2007). The DMPS performed a complete mobility scan every $10 \mathrm{~min}$. Each mobility was set for $12 \mathrm{~s}$ to give adequate sampling time as the counting statistics in the marine environment can be low (Fitzgerald, 1991).

\subsection{Sub-saturated water uptake}

A hygroscopicity tandem differential mobility analyser (HTDMA) was deployed to measure on-line size resolved water uptake between $10 \%$ and 94\% RH. HTDMAs (Liu et al., 1978; McMurry and Stolzenburg, 1989) size select a dry aerosol mobility using a Differential Mobility Analyser (DMA) which is then humidified and sized again using a second DMA which measures the size distribution of the humidified aerosol. In this study an HTDMA was deployed (Cubison et al., 2005) selecting and humidifying to $90 \% \mathrm{RH}$ aerosol particles with dry diameters $\left(D_{0}\right)$ of $24 \mathrm{~nm}$, $43 \mathrm{~nm}, 81 \mathrm{~nm}, 129 \mathrm{~nm}, 169 \mathrm{~nm}, 211 \mathrm{~nm}$ and $254 \mathrm{~nm}$ respectively with $1 \mathrm{~h}$ resolution. Periodically humidograms were recorded where the $\mathrm{RH}$ the particles were conditioned to was 
stepped from $\sim 40 \%$ to $\sim 94 \%$ over $\sim 4$ h for a subset of the 7 dry diameters.

The HTDMA was modified for operation at sea by replacing the water cooling system with an insulated temperature controlled box enclosing the second humidified DMA. A PID (Proportional-Integral-Differential) controlled (using Supercool's PR59 software) peltier cooler (Supercool AA-060-1222) maintained the second DMA a constant temperature of $18 \pm 0.1^{\circ} \mathrm{C}$, approximately $2^{\circ} \mathrm{C}$ lower than the mobile laboratory situated in a container on the foredeck, see Allan et al. (2009). The residence time of the humidified aerosol prior to entering the second DMA was $\sim 15 \mathrm{~s}$. Quality assurance and inversion of the HTDMA data was performed using the procedures and multi-triangle inversion method described by Gysel et al. (2009).

\subsection{Cloud forming potential}

The ability of the aerosol particles to act as Cloud Condensation Nuclei (CCN) is measured using a continuous flow thermal-gradient $\mathrm{CCN}$ counter (Roberts and Nenes, 2005). The CCN counter is calibrated using nebulised monodisperse ammonium sulphate ( $>99.5 \%$, Sigma Aldrich) and sodium chloride ( $>99.5 \%$, Sigma Aldrich) aerosol according to the procedure described in Good et al. (2010). The calibration aerosol is nebulised, dried and size selected using a DMA. The mono-disperse aerosol is then split between a CN counter (TSI, 3010) and the CCN counter. The activated fraction (number of $\mathrm{CCN}$ divided by the number of $\mathrm{CN}$ ) is then measured as a function of the supersatration in the CCN counter's column at a series of $D_{0}$ s between $30 \mathrm{~nm}$ and $130 \mathrm{~nm}$. The supersaturation corresponding to $50 \%$ activated fraction was deemed to be the critical supersaturation (Good et al., 2010). The supersaturation is calibrated using theoretical values from ADDEM (Topping et al., 2005a). The number size distribution produced by the nebuliser is then measured to assess the impact of multiply charged particles, which was found to be negligible owing to the shape of the distribution.

During ambient sampling, the $\mathrm{CCN}$ counter is operated in parallel to a CN counter (TSI, 3010) downstream of a DMPS (the same DMA and CPC used for the calibrations). The DMPS is stepped across 20 diameter bins between approximately $20 \mathrm{~nm}$ and $500 \mathrm{~nm}$, allowing the simultaneous determination of the $\mathrm{CN}$ number size distribution and the CCN number size distribution at a specific supersaturation. The size distributions are measured over a $10 \mathrm{~min}$ period, including 3 min settling time for the temperatures in the $\mathrm{CCN}$ counter. 5 supersaturations $(0.11 \%, 0.18 \%, 0.34 \%, 0.5 \%$ and $0.75 \%$ ) are repeatedly stepped through at $10 \mathrm{~min}$ intervals, an additional $10 \mathrm{~min}$ settling time was added to the step between the highest and lowest supersaturations resulting in a $1 \mathrm{~h}$ measurement resolution. The ambient $\mathrm{CCN}$ and $\mathrm{CN}$ number size distributions are corrected for the effects of multiply charged particles using the charging probability approximations of Wiedensohler (1988) and the methodology described by Good et al. (2010). The CCN counter is operated at an inlet temperature of $\sim 20^{\circ} \mathrm{C}$ throughout the calibrations and ambient measurements.

The simultaneously measured $\mathrm{CN}$ and $\mathrm{CCN}$ number size distributions are used to calculate the activation spectra (the number of $\mathrm{CCN}$ divided by the number of $\mathrm{CN}$ as a function of dry diameter). The activation spectra are then used to define the $D_{50}$ (the $D_{0}$ at which $50 \%$ of the particles activate). The $D_{50}$ defines the critical supersaturation $\left(S_{\mathrm{c}}\left(D_{50}\right)\right.$ where $S_{\mathrm{c}}$ is the $S$ set by the CCN counter whilst the spectra are acquired. This definition of $S_{\mathrm{c}}$ has been applied by various authors interpreting $\mathrm{CCN}$ data, although the precise manner in which the data are processed varies e.g. Rose et al. (2008); Shilling et al. (2007); Prenni et al. (2007).

\subsection{Describing the aerosol composition}

The ionic composition as measured by the AMS is used to determine the composition of the sub- $\mu \mathrm{m}$ aerosol. The mixing rule applied by Zaveri et al. (2005) was used to determine the electrolytes formed from the $\mathrm{SO}_{4}^{2-}, \mathrm{NH}_{4}^{+}$and $\mathrm{NO}_{3}^{-}$ detected by the AMS. The mixing rule defines 2 regimes; sulphate poor and sulphate rich. In sulphate rich regimes, there is an excess number of moles $(n)$ of $\mathrm{SO}_{4}^{2-}$ compared to $n_{\mathrm{NH}_{4}^{+}}$. In sulphate rich conditions the rule provides a method to estimate bisulphate formation. The concentration of $\mathrm{H}^{+}$is automatically defined according to the concentration and stoichiometry of the following salts predicted to occur: $\mathrm{H}_{2} \mathrm{SO}_{4}, \mathrm{HNO}_{3}, \mathrm{NH}_{4} \mathrm{HSO}_{4}, \mathrm{NH}_{4} \mathrm{NO}_{3},\left(\mathrm{NH}_{4}\right)_{2} \mathrm{SO}_{4}$ and $\left(\mathrm{NH}_{4}\right)_{3} \mathrm{H}\left(\mathrm{SO}_{4}\right)_{2}$. The organic mass measured by the AMS is assumed to have a density of $1400 \mathrm{~kg} \mathrm{~m}^{-3}$ and a molecular weight of $500 \mathrm{~g} \mathrm{~mol}^{-1}$ in order to represent to represent larger molecular weight primary marine organic material. The organics are assumed to only interact only with the water and not with the inorganic ions.

It should be noted that only bulk, not size resolved AMS composition is available for this study. This means that we cannot model the size resolved composition dependence of the water uptake from the AMS measurement. This could result in the non-refractory composition being more representitive at sizes closer to the mode of the aerosol mass size distribution.

\subsection{Describing the aerosol water uptake - Köhler theory}

The Köhler equation describes the water uptake as two competing effects, known as the Raoult term and the Kelvin term. Raoult's law describes the ideal relationship between solute and solvent in a dilute solution. Particles in the atmosphere can be present in both concentrated and dilute solutions. Therefore to calculate the amount of solvent (water) associated with each component in the aerosol particle at a specific equilibrium Relative Humidity $(\mathrm{RH})$ the deviation 
from ideality must be known. Activity coefficients for each component describe the non-ideality of the solution and the interactions between all solutes and between the solvent and solutes must be considered in order to explicitly describe the water activity. The Kelvin term acts to increase the equilibrium vapour pressure of water vapour above a curved surface. By coupling the Kelvin and Raoult terms the equilibrium conditions for a particle are described. The magnitude of the Kelvin term increases for smaller particles i.e. as the curvature increases.

The most complete model approaches search for the global Gibbs free energy minimum whilst allowing for interactions between all components present for example Topping et al. (2005a,b). Analytical determination of the Kelvin term which manifests itself through the surface tension of the solution droplet and subsequent change to the solution bulk caused by the removal of surfactants to the surface layer is non-trivial for most multi-component systems. Aerosol thermodynamic models have so far only been used to rigorously apply Gibbsian thermodynamics to simple (binary and ternary) systems to calculate the surface tension and bulk effect of the Kelvin term (Li et al., 1998; Sorjamaa et al., 2004; Topping et al., 2007).

A detailed analysis of the errors associated with the commonly used assumptions is presented by Brechtel and Kreidenweis (2000). The most simplified form of the Kelvin term uses two main assumptions; that the surface tension is equal to that of pure water and that the partial molar volume of water can be replaced by the molar volume of water (Kreidenweis et al., 2005).

In the current study the $\kappa$-Köhler-model (Petters and Kreidenweis, 2007) is applied and investigated. The $\kappa$-model represents the relationship between water activities and the solution strength using a single parameter $\kappa$, such that:

$a_{\mathrm{w}} \equiv\left(1+\kappa \frac{V_{\mathrm{s}}}{V_{\mathrm{w}}}\right)^{-1}$

where $a_{\mathrm{w}}$ is the water activity, $V_{\mathrm{s}}$ is the volume of solute and $V_{\mathrm{w}}$ is the volume of water, thereby capturing the compositional information. $\kappa$ can then derived from measurements of a particle's water uptake or theoretically from a thermodynamic model when combined with a suitable expression for the Kelvin term. Petters and Kreidenweis (2007) suggest that the Kelvin term can be represented as:

$K_{\mathrm{e}}=\exp \left(\frac{4 v_{\mathrm{w}} \sigma_{\mathrm{sol} / \mathrm{v}}}{R T D}\right) \approx \exp \left(\frac{4 \sigma_{\mathrm{w}} M_{\mathrm{w}}}{R T \rho_{\mathrm{w}} D}\right)$

where $K_{\mathrm{e}}$ is the Kelvin term, $v_{\mathrm{w}}$ is the partial molar volume of water, $\sigma_{\mathrm{sol} / \mathrm{v}}$ is the surface tension of the solution droplet, $\sigma_{\mathrm{w}}$ is the surfaced tension of water, $M_{\mathrm{W}}$ is the molecular weight of water, $R$ is the universal gas constant, $T$ is the temperature, $\rho_{\mathrm{w}}$ is the density of water and $D$ is the droplet diameter. The assumptions being made are that the surface tension is equal to that of pure water and that the partial molar volume of water can be represented by the molar volume of water. Combining 1 and 2 gives:

$\mathrm{RH}=\frac{\mathrm{GF}_{\mathrm{D} 0, \mathrm{RH}}^{3}-1}{\mathrm{GF}_{\mathrm{D} 0, \mathrm{RH}}^{3}-(1-\kappa)} \exp \left(\frac{4 \sigma_{\mathrm{w}} M_{\mathrm{w}}}{R T \rho_{\mathrm{w}} D_{0} \mathrm{GF}_{\mathrm{D} 0, \mathrm{RH}}}\right)$

Where the droplet size is represented in terms of the the hygroscopic growth factor $\left(\mathrm{GF}_{\mathrm{D} 0, \mathrm{RH}}\right) ; D$ divided by $\left(D_{0}\right)$. The validity of the assumptions within Eqs. 1 and 2 is based primarily on data from single component aerosol particles. For example taking measured and modelled data (thermodynamically rigorous models e.g. Clegg et al., 1998) for a selection of inorganic and organic aerosols over a range over conditions (RHs and $D_{0}$ s) it is seen that generally their hygroscopic behaviour falls on lines of constant $\kappa$ within measurement error (Petters and Kreidenweis, 2007). There have however been few atmospheric studies where the $\kappa$ model has been used to parameterise the measured and predicted aerosol water uptake (Petters and Kreidenweis, 2007). Therefore it has been cautioned that the sparsity of atmospheric CCN studies in particular limits the broad generalisations that can be made especially since the accuracy with which aerosol water uptake needs to be described in pertinent applications (e.g. climate models) is not well defined (Petters and Kreidenweis, 2007).

As $\kappa$ is derived directly from measured or modelled data, by definition it will give the "correct" answer at the input conditions. So an initial test of the model's general applicability will be to see if it gives acceptable results over the range of RHs and dry sizes found in atmospheric environments. The applicability of the $\kappa$ parameter as a function of particle size and RH has been assessed for a wide variety of aerosols of known composition and generally gives consistent $\kappa$ values $( \pm 20 \%)$ (Petters and Kreidenweis, 2007; Kreidenweis et al., 2008). Secondly the $\kappa$-model offers a way to parameterise atmospheric CCN activity; for example it may be possible to describe the hygroscopicity in broad aerosol classes e.g. marine or continental in terms of just a single $\kappa$ for modelling purposes (Andreae and Rosenfeld, 2008). In this paper the applicability of the $\kappa$-model will be tested in both these respects for the aerosol in the marine boundary layer of the cruise region. The variability of $\kappa$ as a function of dry size over a range of sub-saturated RHs and at the point of activation was determined.

\subsection{Predicting aerosol hygroscopicity using the AMS}

The ZSR mixing rule (Stokes, 1966) was used to predict the growth factor of the aerosol particles at $90 \% \mathrm{RH}$, by adding the volume weighted growth factors of their individual components (Gysel et al., 2007) using Eq. 4. The growth factors of the inorganic solutes (as determined by the scheme in Sect. 2.4) were calculated using ADDEM (Topping et al., 2005a), a detailed thermodynamic model capable of predicting single component inorganic aerosol growth factors with 
high accuracy and precision. The hygroscopicity of the organic fraction was estimated to be equivalent to a $\kappa$ value of 0.085 which is equivalent to a growth factor of $\sim 1.2$ at $90 \%$ relative humidity (for $D_{0}=\infty$ ). The assumed organic $\kappa$ value was used within Eq. 3 to estimate its size dependent growth factor. The pure component growth factors were then combined using the volume fractions to predict the ensemble growth factor using Eq. 4. To calculate the volume fraction of the organic aerosol its density was assumed to be $1400 \mathrm{~kg} \mathrm{~m}^{-3}$, representitive of oxidised organic aerosols (Alfarra et al., 2006; Dinar et al., 2006; Gysel et al., 2007). To test the sensitivity of the predictions to the choices of the organic's properties densities of 1200 and $1600 \mathrm{~kg} \mathrm{~m}^{-3}$ and $\kappa$ values of 0.01 and 0.2 were also applied. The sensitivity of the predicted ensemble particle growth factors to the organic density was $< \pm 0.015$ and to the organic $\kappa$ was $< \pm 0.03$, both relatively small changes.

$\mathrm{GF}(\mathrm{RH}) \approx \sum_{i}\left(\epsilon_{i} \mathrm{GF}_{i}(\mathrm{RH})^{3}\right)^{1 / 3}$

The $\kappa$ value for an ensemble particle can be defined in terms of the sum of its components $\kappa$ values using the ZSR mixing rule in exactly the same manner as described for the growth factor in Eq. 4, such that the ensemble $\kappa$ is defined as the volume weighted sum of its component's $\kappa$ values. The $\kappa$ value derived a particle of a given composition may vary, depending upon the size and RH it is derived at. This can be due to the non-ideality of the solution and/or that the representation of the Kelvin term such that Eqs. 3 and 2 are not is not strictly followed. Therefore the $\kappa$ value derived from the growth factor at $90 \% \mathrm{RH}$ using the AMS composition as input will not necessarily be the same as predicted at the point of activation for the same particle. What is assumed is that the any change in $\kappa$ with RH or $D_{0}$ is not large enough to significantly bias the end product e.g. CCN number. Table 1 shows the pure component $\kappa$ values derived from the ADDEM predicted growth factors at $90 \% \mathrm{RH}$ at $D_{0} \mathrm{~s}$ of 30 , 100 and $300 \mathrm{~nm}$.

\subsection{Parameterising the aerosol hygroscopicity}

The Raoult term in the Köhler equation was parameterised using the hygroscopicity parameter $\kappa . \quad \kappa$ values are derived independently from the AMS (non-refractory composition), HTMDA (hygroscopic growth factor) and CCN counter (critical supersauration) measurements. $\kappa$ values are derived from the AMS by first predicting the growth factor at $90 \% \mathrm{RH}$ as described in Sect. 2.6. Once $\mathrm{GF}_{\mathrm{D} 0, \mathrm{RH}}$ is predicted a corresponding $\kappa$ value can be computed directly using Eq. 3. The hygroscopic growth factor measured by the HTDMA at $90 \%$ RH was also used to calculate $\kappa$ by taking mean $\mathrm{GF}_{\mathrm{D} 0,90}$ from each measured growth factor probability density distribution and Eq. 3. Similarly using $S_{\mathrm{c}}\left(D_{0}\right)$, $\kappa$ values were derived from the $\mathrm{CCNc}$ measurements. Thus a time series of $\kappa$ values from: (i) the AMS ( $\left.\kappa_{\mathrm{AMS}}\right)$ using
Table 1. $\kappa$-values for particles derived from ADDEM predictions of $\mathrm{GF}_{\mathrm{D} 0,90}$ for the inorganic compounds formed by the mixing rule.

\begin{tabular}{lrrr}
\hline Compound & $\kappa_{\text {HTDMA, 30 nm }}$ & $\kappa_{\text {HTDMA, } 100 \mathrm{~nm}}$ & $\kappa_{\text {HTDMA,300 nm }}$ \\
\hline $\mathrm{H}_{2} \mathrm{SO}_{4}$ & 1.103 & 0.915 & 0.870 \\
$\mathrm{HNO}_{3}$ & 1.243 & 1.043 & 0.999 \\
$\mathrm{NH}_{4} \mathrm{HSO}_{4}$ & 0.686 & 0.556 & 0.543 \\
$\mathrm{NH}_{4} \mathrm{NO}_{3}$ & 0.754 & 0.622 & 0.597 \\
$\left(\mathrm{NH}_{4}\right)_{2}\left(\mathrm{SO}_{4}\right)$ & 0.626 & 0.509 & 0.483 \\
$\left(\mathrm{NH}_{4}\right)_{3} \mathrm{H}_{\left(\mathrm{SO}_{4}\right)_{2}}$ & 0.750 & 0.611 & 0.579 \\
\hline
\end{tabular}

the inorganic ions and organics (ii) the HTDMA $\left(\kappa_{\text {HTDMA }}\right)$ using the mean $\mathrm{GF}_{\mathrm{D} 0,90}$ and (iii) the $\mathrm{CCN}$ counter $\left(\kappa_{\mathrm{CCN}}\right)$ using $S_{\mathrm{c}}\left(D_{0}\right)$ as input were derived.

\subsection{Predicting the potential of the aerosol particles to act as CCN}

Once $\kappa$ values from the 3 different derivations ( $\kappa_{\text {AMS }}$, $\kappa_{\mathrm{HTMDA}}$ and $\kappa_{\mathrm{CCN}}$ ) have been established, they can be used to predict the $\mathrm{CCN}$ number using the measured number size distributions as a function of supersaturation using the $\kappa$-model. The $\kappa$-model formulation presented here has only one hygroscopicity dependent parameter $(\kappa)$ and therefore any $\kappa$ and $D_{0}$ pair can only be described by a single " $\kappa$-Köhler" curve (at a single temperature). If the hygroscopicity of the entire number size distribution is represented using a constant $\kappa$ value for a given supersaturation there will be a minimum diameter above which the particles will be deemed as potential CCN. These threshold diameters ( $\left.D_{\text {thres }}\right)$ can be calculated by holding $\kappa$ constant and searching for the $D_{0}$ which gives the critical supersaturation equal to the required supersaturation. $D_{\text {thres }}$ is then used to estimate the CCN number as a function of supersaturation using the ambient number size distribution to define the $\mathrm{CN}$ number at each $D_{0}$. Thus integrating the ambient number size distribution from $D_{\text {thres }}$ to the largest measured $D_{0}(\sim 700 \mathrm{~nm})$ gives the potential CCN number at a given supersaturation.

\section{Results}

The results of this study are presented in the context of 3 case study periods, broadly characterised by their distinctive meteorological conditions and represent the prevalent sampling conditions during the scientific phase of the D319 cruise. ECMWF back trajectories (Allan et al., 2009) were used to classify the air masses. Figure 1 shows the cruise track of the Discovery with the 3 periods indicated. Period 1 was from 25 May 2008 18:00:00 UTC to 27 May 2008 10:00:00 UTC and was characterised by 5 day back trajectories originating from the North over the open ocean. During this period, the aerosol number size distribution is typical of the remote marine boundary layer, with low total 


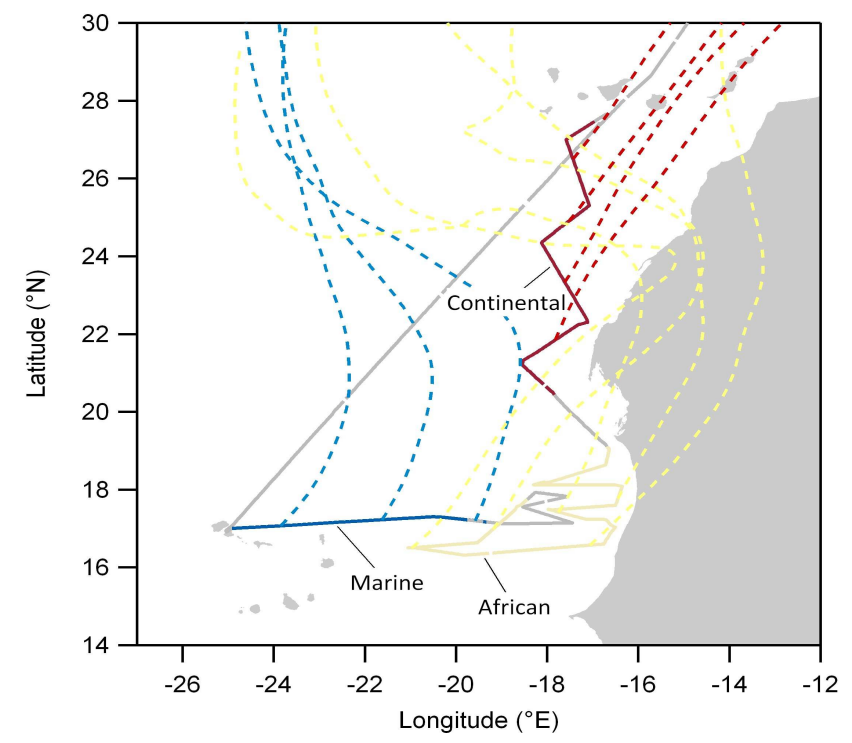

Fig. 1. Discovery D319 cruise track. The coloured sections of the track indicate the 3 study periods. The grey sections transitions between study periods. 5 day back-trajectories are shown along the track to illustrate the air mass origins.

number $\left(<1000\right.$ particles per $\left.\mathrm{cm}^{3}\right)$ and distinct Aitken and Accumulation modes. Period 2 (28 May 2008 14:00:00 UT to 1 June 2008 14:00:00 UT) is characterised by air masses which have been influenced by the African mainland. The total aerosol number concentration during the African period is higher than the Marine period ranging from $\sim 2000$ to 5000 particles $\mathrm{cm}^{-3}$. Comparing the number size distributions measured during the Marine and African periods it is additional Aitken sized particles which contribute the majority of the additional number. During Period 3 (2 June 2008, 08:00:00 UT to 4 June 2008, 10:00:00 UT), the air masses are more varied but generally show northerly trajectories originating in southern continental Europe and passing over the Canary Islands. Figure 2 shows the average number size distributions for each period and their variability.

\subsection{Aerosol composition}

During Period 1, the non-refractory composition is dominated by inorganic compounds, with organic compounds making up $\sim 20 \%$ of the mass for the period. In order to estimate the fraction of the aerosol accounted for by the AMS the masses of each ion are converted to volumes assuming densities for each. The lower panel in Fig. 3 shows the volume fraction of the ions detected by the AMS with respect to the volume measured by the DMPS across the particle diameters measured by the AMS. Comparing the total particle mass derived from the DMPS to the total AMS mass loadings for the period indicates that a large fraction of the sub- $\mu \mathrm{m}$ aerosol is accounted for by the AMS. Analysis of the sub- $\mu \mathrm{m}$ impactor samples show sulphate and ammonium are

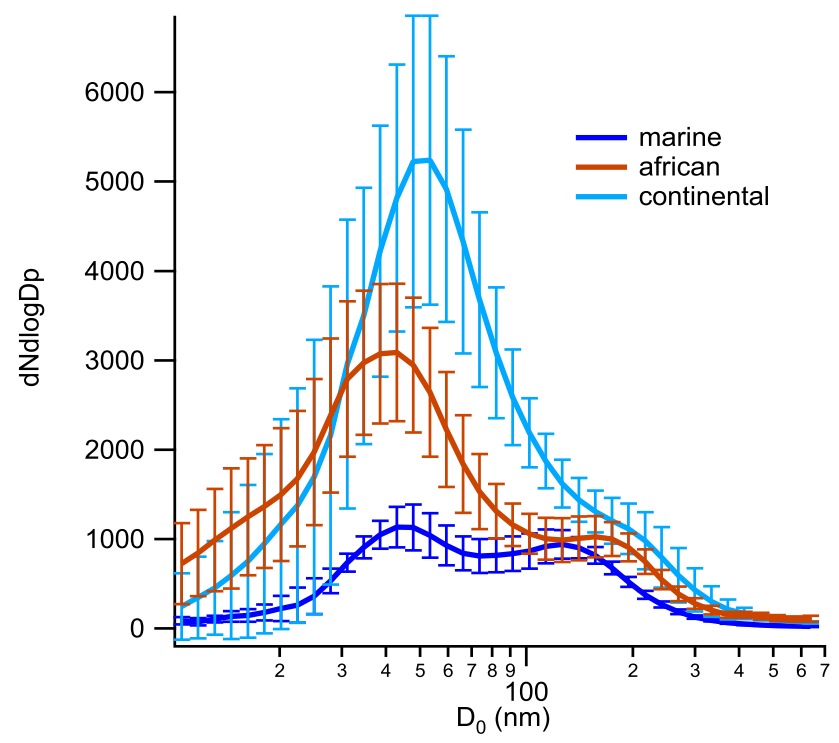

Fig. 2. The average number size distribution for each of the 3 study periods.

the dominant ions, with a relatively small contribution from the other ions detected. The upper panel in Fig. 3 shows the mass fraction of each ion detected from the impactor analysis normalised to the sulphate. Further details of Period 1 are given in Allan et al. (2009).

During Period 2 the total volume derived from the AMS comprises about half of the DMPS derived volume (upper panel Fig. 3), indicating a substantial fraction of the aerosol below $1 \mu \mathrm{m}$ is refractory. The impactor analyses for the period (lower panel Fig. 3) confirm this observation; there are significant fractions of Sodium, Chloride, Calcium and Magnesium. As a result of their production mechanisms Sodium and Chloride tend to make up a significant fraction of large marine aerosol particles (Blanchard and Woodcock, 1957; D. and Smith, 1993; Tegen and Lacis, 1996) $(>1 \mu \mathrm{m})$ whilst smaller particles tend to have larger fractions of sulphate and organics. This is observed in the impactor analysis where the modes of the Calcium, Chloride and Sodium mass distributions are seen at larger sizes than sulphate and with decreasing particle size the fraction of sulphate compared to these ions increases substantially. Therefore the presence of Calcium, Sodium and Chloride ions does not mean there will necessarily be a large mass fraction of the individual particles in the number modes $(<200 \mathrm{~nm})$ where the majority of potential CCN reside. However during Period 2 there is strong evidence of a Sodium Chloride dominated mode and an insoluble fraction (pertaining to a mineral dust source) in the hygroscopic growth factor distributions at $D_{0}$ of $127 \mathrm{~nm}$ and above (Allan et al., 2009).

During Period 3 the AMS total volume loading appears to capture a large fraction of the DMPS derived volume. The impactor analysis shows the higher Calcium fractions which 
persisted through Period 2 are no longer present and that sulphate and ammonium comprise the majority of the ionic mass which is consistent with the AMS detecting a large fraction of the aerosol mass.

\subsection{Measured growth factors}

Growth factor probability density distributions were measured as described in Sect. 2.2. During Period 1 the growth factors fall into a single dominant mode between 1.56 and 1.74 at $90 \%$ RH. The smaller sized particles tend to have lower growth factors. During Period 2, up to three distinct growth factor modes are detected; a mode between $\sim 1.6$ and $\sim 1.8$ comprises the largest number fraction, a mode at between $\sim 1.8$ and $\sim 2.2$ becomes more prominent for the larger dry sizes and a hydrophobic mode appears occasionally for the largest sizes. During Period 3 the growths factors tend to fall within a single mode with the mean growth factor varying between 1.48 and 1.8 , although a mode between $\sim 1.8$ and $\sim 2.2$ does appear sometimes at larger sizes. Figure 4 shows the retrieved growth factor probability density distributions for the $D_{0} \mathrm{~s} 43,127$ and $254 \mathrm{~nm}$ for each of the periods. Figure 4 illustrates the differing behaviour between the periods and as a function of dry size.

The hydrophobic mode is likely to result from sampling of dust particles. The dominant mode which appears between 1.48 and 1.8 depending on the period is consistent with sulphate aerosol particles, with a varying influence from organic components. The mode between $\sim 1.8$ and $\sim 2.2$ during Period 2 is likely due in part to the influence of Sodium Chloride and is consistent with the increased Sodium and Chloride levels from the impactor analysis. The resolution of the HTDMA is limited by the system's transfer function (Cubison et al., 2005) and therefore it is not always clear if there is a continuum of growth factors or distinct modes particularly in the externally mixed cases. Additional analysis of the measured growth factors is presented in Allan et al. (2009).

\subsection{Prediction and parameterisation of the sub-saturated water uptake}

The hygroscopic growth factor at $90 \% \mathrm{RH}$ was predicted using the sub- $\mu \mathrm{m}$ ionic composition measured by the AMS as input. Figure 5 shows the growth factors predicted from the AMS measured composition plotted against the corresponding measured values. The ability to predict the growth factor varies between the 3 case study periods. For Period 1 the measured mean growth factors vary between 1.56 and 1.74, the predicted growth factors between 1.54 and 1.72. The spread of predicted growth factors largely results from the Kelvin effect reducing the growth factor of smaller particles rather than variability in the compositional input. During Period 2 the range of measured growth factors is relatively large; from 1.46 to 1.91 whilst the predicted growth factors vary only as a function of their dry diameter between 1.56

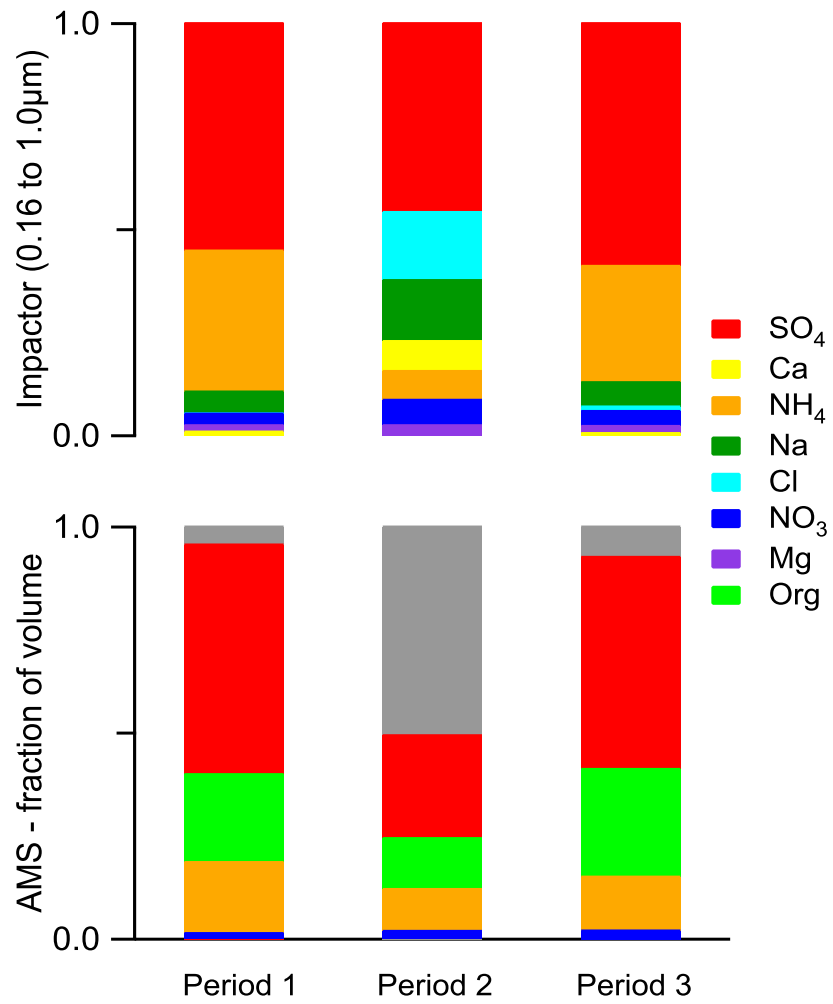

Fig. 3. Aerosol composition for the 3 case study periods. The top panel shows the mass fraction of each ion normalised to sulphate from analysis of the impactor samples in the $0.16 \mu \mathrm{m}$ to $1.0 \mu \mathrm{m}$ stage averaged over each study period. The bottom panel shows the composition (converted to volume) measured by the AMS averaged over each period as a fraction of the averaged total aerosol volume measured by the DMPS. The individual compounds are indicated by colour: sulphate (red), ammonium (orange), calcium (yellow), sodium (dark green), chloride (light blue), nitrate (dark blue), magnesium (purple) and organics (light green). The grey bands indicates the differences between the AMS and DMPS volumes.

and 1.67. During Period 3, there is well correlated variability between the measured and predicted growth factors. The measured growth factors vary from 1.48 to 1.8 , whilst the predicted growths factors vary from 1.42 to 1.85 .

The agreement between the DMPS volume and the AMS volume during Period 1 shows that a large fraction of the aerosol is non-refractory and the ionic composition derived from the AMS for input to the mixing rule should be representative. The growth factor predictions during Period 1 on average agree very well with the predicted values, with the differences consistent with the measurement and model uncertainties. The variability resulting from the uncertainty makes it difficult to say whether there is a correlation, but there seems to be overall agreement. This could be a result of the small range of the values and the low mass and number concentrations during the period making the data noisy. Values of the hygroscopicity parameter $\kappa$ were predicted for the average measured and predicted growth factor at each 


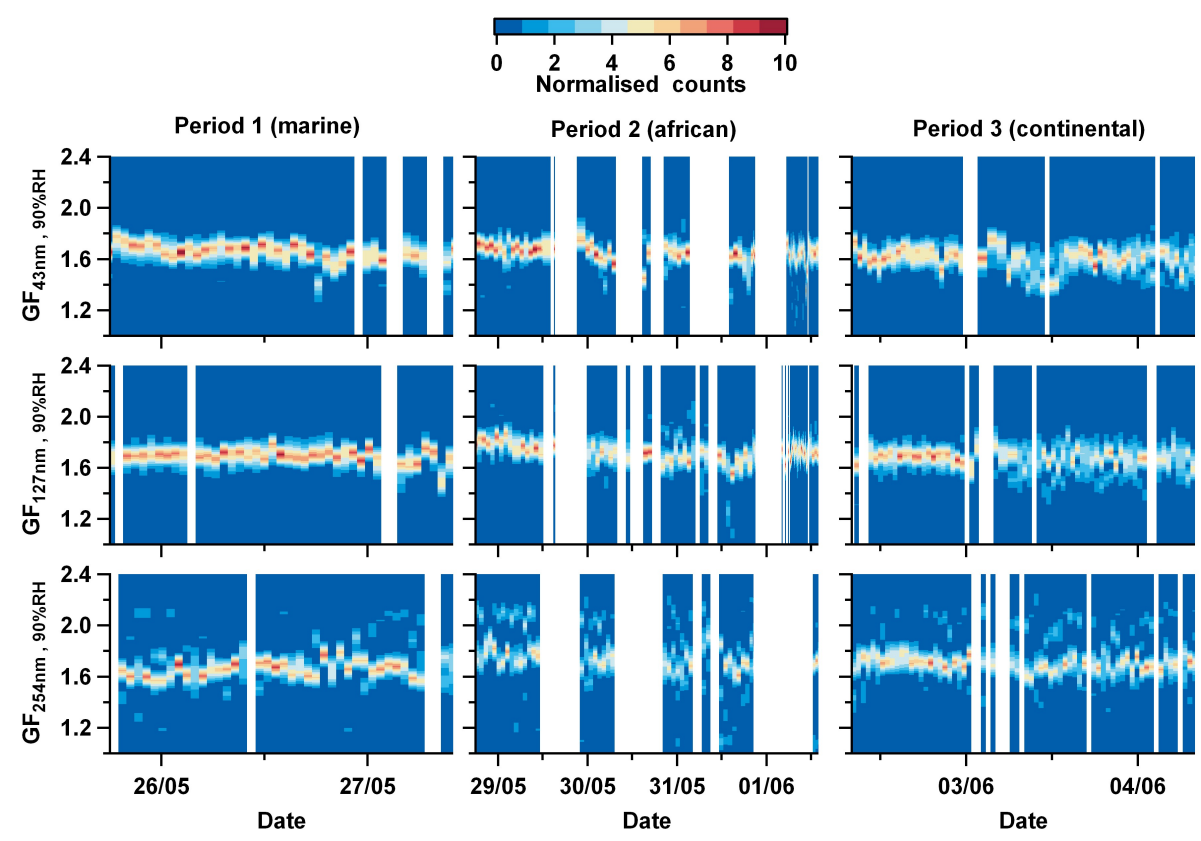

Fig. 4. The retrieved growth factor probability density distributions for the 3 study periods at $90 \%$ RH for $D_{0}$ s of 43,127 and $254 \mathrm{~nm}$. White gaps indicate periods when the HTDMA was performing humidograms or was being calibrated.

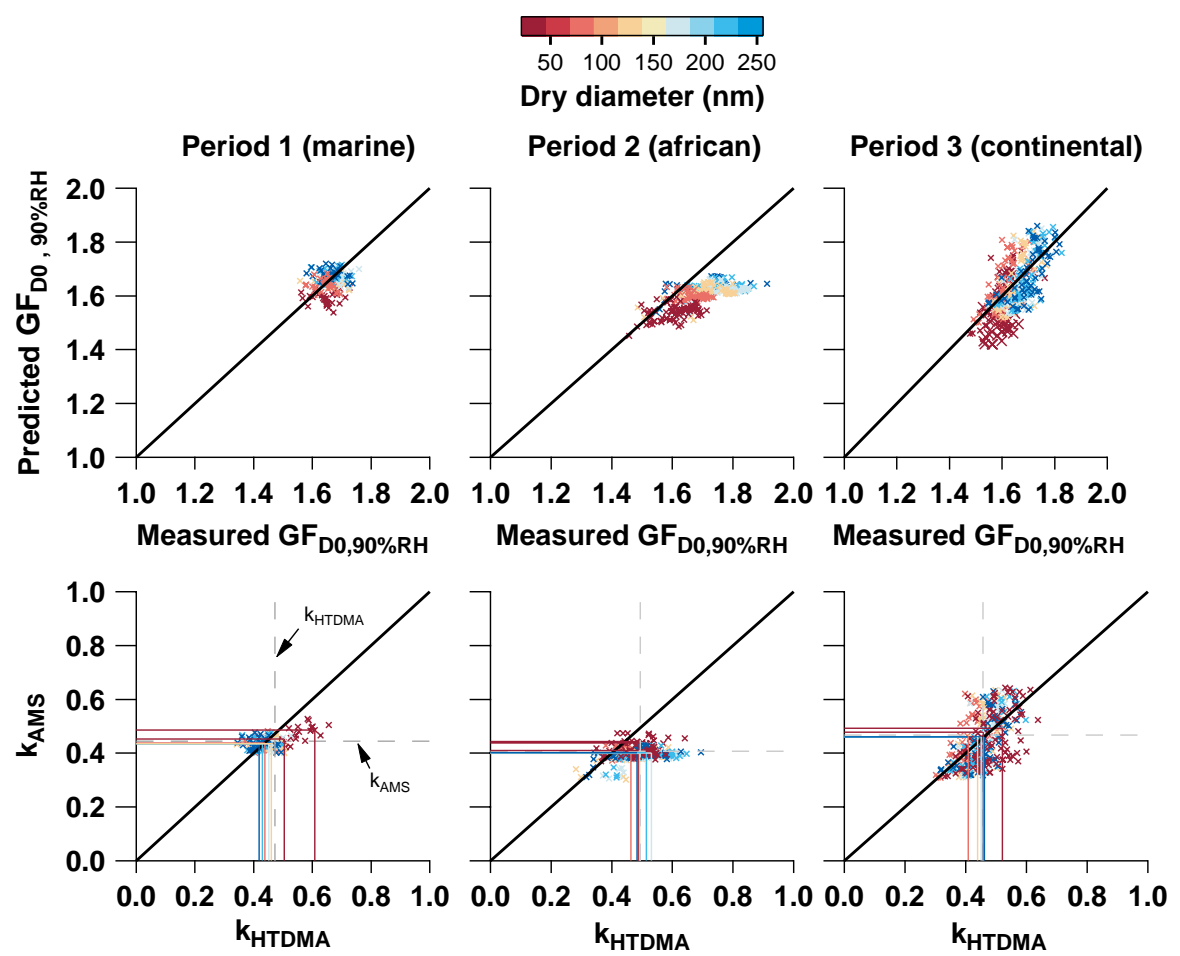

Fig. 5. Measured and predicted growth factors. The top panels show the predicted growth factors plotted against the measured growth factors at each measurement interval for the 3 study periods (marine, african and continental). The coloured lines show the average $\kappa$ values for each dry size. The grey lines show the averaged $\kappa$ values for the entire period. The bottom panels show the $\kappa$ values corresponding to the predicted and measured growth factors for the 3 periods. 

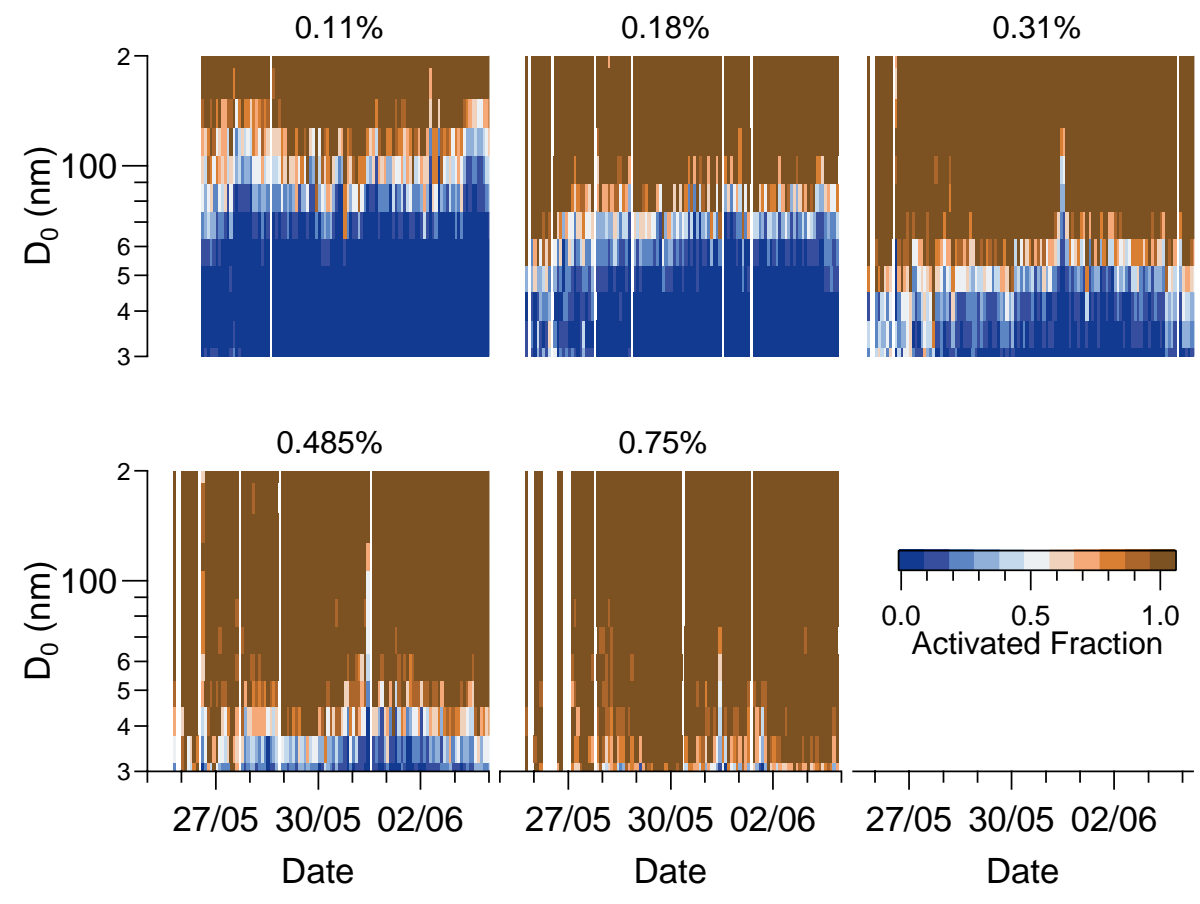

Fig. 6. Time series of the fraction of $\mathrm{CN}$ activation into $\mathrm{CCN}$ as a function of $D_{0}$ at the set supersaturations. The 5 panels correspond to the 5 supersaturations set by the CCN counter $(0.11 \%, 0.18 \%, 0.31 \%, 0.485 \%$ and $0.75 \%)$. The left hand axes is the $D_{0}$ and the colour scale is the activated fraction.

measured dry diameter. Best agreement is found at the larger sizes; the smallest diameter $(24 \mathrm{~nm})$ giving the largest difference in $\kappa$ values. The dry size dependent $\kappa$ values were then used to produce an evenly weighted average $\kappa$ across the size range of $20 \mathrm{~nm}$ to $300 \mathrm{~nm}$. The average $\kappa$ derived from the measured growth factors was 0.47 . The average $\kappa$ derived from the predictions was 0.45 .

During period 2 there was generally a significant difference between the DMPS volume and AMS derived total mass, by on average a factor of $\sim 2$ (illustrated in Fig. 3). The fact that there is a significant refractory mass fraction means that the growth factor predictions may not be accurate. The impactor measurements (Fig. 3) show significantly increased fractions of sodium, chloride and non sea salt calcium during Period 2, these ions are not detected by the AMS and are therefore likely to account for the discrepancy. It is also likely that it is this "missing" composition that causes the variability in the measured growth factors that is not seen in the model predictions. Further evidence is seen on examination of the growth factors distributions where there is clear evidence of an externally mixed more hygroscopic mode for the larger dry diameters $(127 \mathrm{~nm}$ and above). The growth factors of the particles in the more hygroscopic modes are consistent with particles containing sodium chloride. The $\kappa$ values averaged across all sizes derived from the measured growth factors is 0.495 and from the modelled growth factors is 0.41 .
During Period 3 the DMPS-derived total volume concentrations show good agreement with the AMS indicating that a large fraction of the composition will be captured in the model input. The predicted and measured growth factors during Period 3 show good agreement with the measurement and model uncertainties. On average the predicted growth factors are higher than the measured values. The average $\kappa$ values from the measured growth factors is 0.46 and from the predicted values is 0.47 . In summary: For Periods 1 and 3, there is good agreement within the measurement and model uncertainties. For Period 2 the model tends to under-predict the growth factors and does not capture their variability, this is caused by the significant refractory aerosol fraction. The lower panels in Fig. 5 show the comparisons between $\kappa_{\text {AMS }}$ and $\kappa_{\mathrm{HTDMA}}$.

\subsection{Measured CCN activity}

The fraction of particles activating as a function of their dry diameter was measured at 5 set supersaturations. Figure 6 shows the activated fraction as a function of dry diameter at each set supersaturation. The activated fraction increases with dry size as expected, the variability in activated fraction with time at constant diameter is caused by the changing aerosol composition. Sigmoids are fitted to the averaged spectra at each set supersaturation from which the $D_{50}$ is calculated, defining the critical supersaturation $\left(S_{\mathrm{c}}\left(D_{50}\right)\right)$. In the current study, the sigmoids fit closely to the measured 

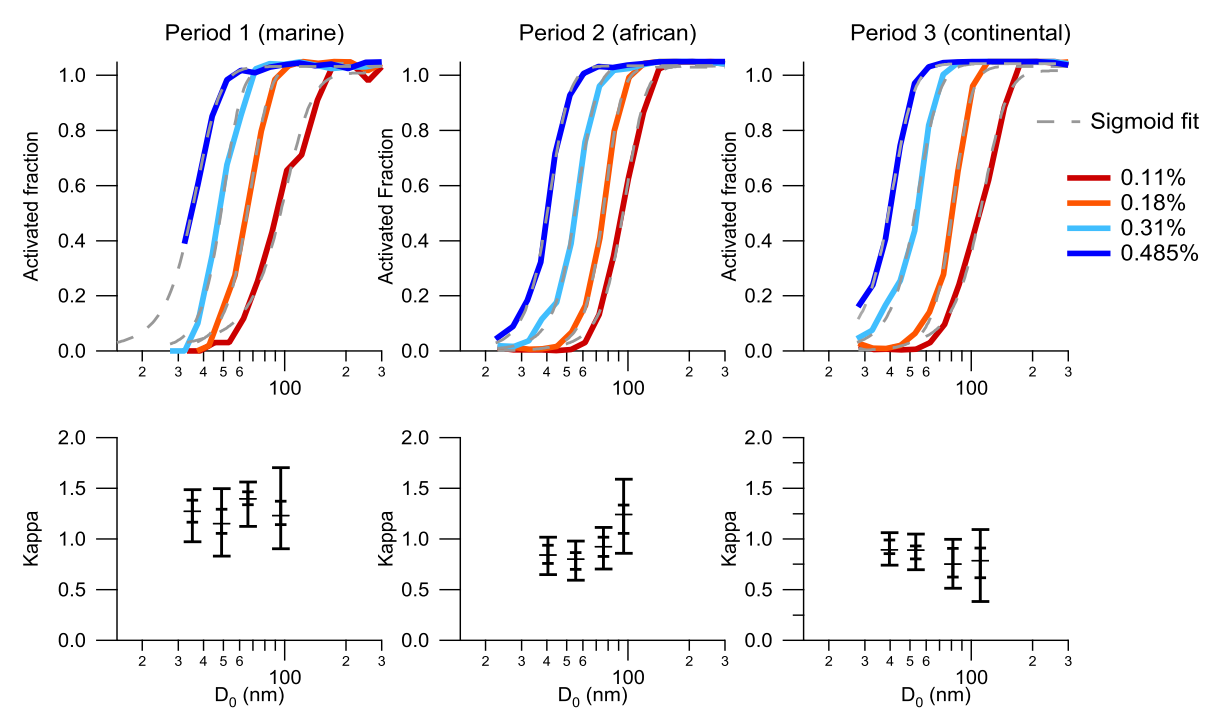

Fig. 7. Averaged CCN data and derived $\kappa$ values for the 3 study periods. The upper panels show the averaged CCN activation spectra at the set point supersaturations $(0.11 \%, 0.18 \%, 0.31 \%$ and $0.485 \%)$. The sigmoid fits for each activation spectrum are overlaid (dash grey lines). The lower panels show the $\kappa$ values derived from the $D_{50}$ at each set supersaturation. The error bars show the range of $\kappa$ values in the 10 th, 25th, 75th and 90th percentiles.

values so a higher order fit function is not required. From the $\left(S_{\mathrm{c}}\left(D_{50}\right)\right)$ derived from each activation spectra are then used to calculate their corresponding $\kappa$ values by solving Eq. 1 iteratively. The activation spectra averaged over each case study period are shown in Fig. 7 for each period for each supersaturation set point up to $0.485 \%$. At $0.75 \%$ the aerosol particles are generally close to $100 \%$ activated at all the measured sizes.

During Period 1 the aerosol particles are most $\mathrm{CCN}$ active. The average $\kappa$-values derived from each activation spectra at $0.11 \%$ to $0.485 \%$ were between 1.15 and 1.40 (shown in the left hand lower panel of Fig. 7). There is no significant trend in $\kappa$ with dry size.

The CCN activity measured during Period 2 shows a step in the derived $\kappa$ at $0.11 \%$ supersaturation (Fig. 7 lower centre panel). The $\kappa$ values for $D_{0}$ below $100 \mathrm{~nm}$ are between 0.8 and 0.92 whilst the $\kappa$ for $110 \mathrm{~nm}$ is 1.24 . This change in $\kappa$ is perhaps indicative of a change in composition with increasing $D_{0}$. The same trend is observed in the HTDMA measurements of the sub-saturated water uptake, which show an increase in the growth factors with dry size beyond that caused by the Kelvin effect alone.

During Period 3 the $\kappa$ values range from 0.89 to 0.75 (Fig. 7 lower right hand panel). The $\kappa$ values derived at $0.11 \%$ and $0.18 \%$ supersaturation are slightly lower than those derived at the higher supersaturations, but the difference is within measurement uncertainty.

\subsection{CCN predictions}

The $\kappa$ values using the AMS composition as input ( $\left.\kappa_{\mathrm{AMS}}\right)$ and using the HTDMA ( $\left.\kappa_{\text {HTDMA }}\right)$ as input were compared to the values derived from the $\mathrm{CCN}$ measurements $\left(\kappa_{\mathrm{CCN}}\right)$. The $\kappa$ values from Period 1 show that the particles measured by the $\mathrm{CCN}$ counter are more $\mathrm{CCN}$ active than either the AMS or HTDMA derived $\kappa$ values suggests. $\kappa_{\mathrm{CCN}}$ measured during Period 2 are higher than $\kappa_{\mathrm{AMS}}, \kappa_{\mathrm{HTDMA}}$ is higher than $\kappa_{\mathrm{AMS}}$ and therefore closer to $\kappa_{\mathrm{CCN}}$, but generally still lower. During Period $3 \kappa_{\mathrm{AMS}}, \kappa_{\mathrm{HTDMA}}$ and $\kappa_{\mathrm{CCN}}$ are in closest agreement, the measured $\kappa$ values being only slightly higher than the predicted values.

To analyse the effect of the differences in $\kappa$ values the measured and predicted CCN number are compared. This is done using the averaged number size distributions for each period. The range of $\kappa$ values from each period for each of the inputs (CCN, HTDMA and AMS) were used to predict the minimum dry diameter for CCN activation ( $\left.D_{\text {thres }}\right)$ for supersaturations between $0.01 \%$ and $1 \%$. The $D_{\text {thres }}$ was used to predict the potential $\mathrm{CCN}$ number at each supersaturation by integrating the number size distribution for $D_{0}>D_{\text {thres. }}$. The differences in the measured and predicted $\mathrm{CCN}$ number for the 3 periods (illustrated in Fig. 8) can be summarised as follows:

1. (i) For Period 1 there is a systematic under-prediction of the potential CCN number by $\sim 10 \%$ to $\sim 20 \%$ at supersaturations above $0.2 \%$ The percentage difference increases at supersaturations below $0.2 \%$, owing to the fact that the $D_{\text {thres }}$ values are close to the edge of the size distribution.

2. (ii) For Period 2 the agreement depends quite strongly on the $\kappa$ values chosen. Choosing the averaged values from the 3 derivations of $\kappa$ gives a difference of $\sim 20 \%$ 


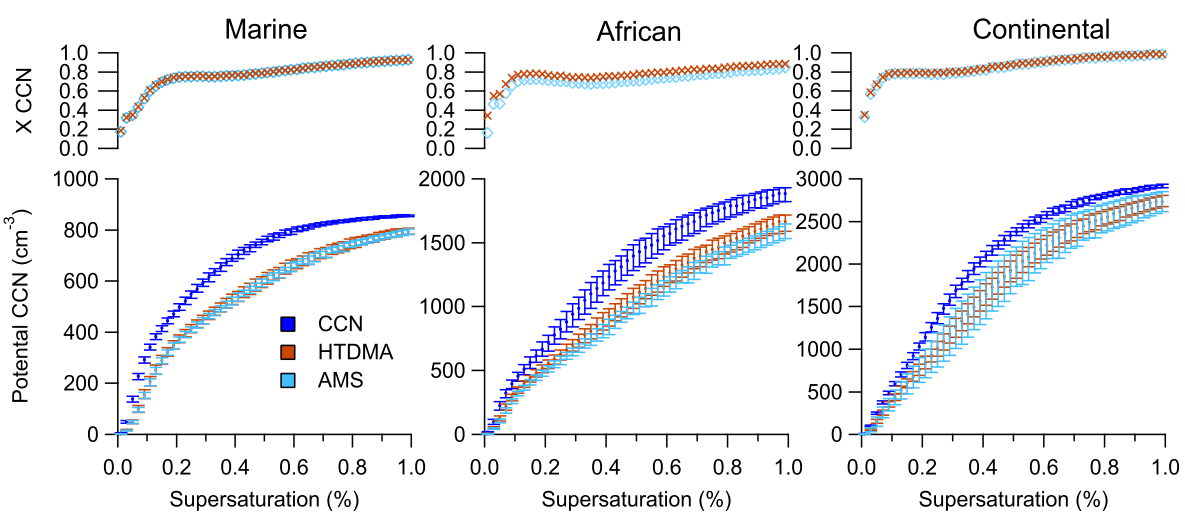

Fig. 8. CCN concentrations as a function of supersaturation for the 3 study periods. The top panels show the fraction of the $\mathrm{CCN}$ counter derived CCN concentration predicted from the AMS and HTDMA (X CCN=CCN $\left.\mathrm{Credicted} / \mathrm{CCN}_{\text {measured }}\right)$. The bottoms panels show the $\mathrm{CCN}$ concentrations based on the $\kappa$ parameterisations derived from the AMS (light blue symbols), HTDMA (brown symbols) and CCN counter (dark blue symbols). The error bars on the AMS and HTDMA derived concentrations represent the 10th and 90th percentile $\kappa$ values for the respective period. The error bars on the $\mathrm{CCN}$ counter derived concentrations represent the range of $\kappa$ values from the period averaged $\mathrm{CCN}$ data.

to $\sim 30 \%$, but by choosing "optimum" values at the limits of the respective ranges gives a difference of $\sim 5 \%$.

3. (iii) For Period 3 there is a smaller under prediction than Periods 1 and 2. The difference is largest at lower supersaturations, $\sim 10 \%$ to $\sim 20 \%$ below $0.3 \%$ supersaturation. The difference reduces to less than $5 \%$ at higher supersaturations. The range of $\kappa_{\mathrm{AMS}}$ and $\kappa_{\mathrm{HTDMA}}$ values is relatively wide in the period, indicating a variability of historical influences on the air mass being sampled consistent with the back trajectories described earlier (as illustrated in Allan et al., 2009 and Lee et al., 2010).

The increase in the discrepancy for supersaturations below $0.2 \%$ cause by the shape of the number size distribution, may turn out to be important. Supersaturations in stratiform clouds tend to peak at fairly low values, in the range of $0.15 \%$ to $0.4 \%$ (Martin et al., 1994; Hudson and Svensson, 1995; Hoppel et al., 1996). Therefore the discrepancy appears largest for atmospherically relevant supersaturations.

\subsection{Reconciliation}

Based on the observation that for each period the CCN activity is under-predicted, possible causes of this discrepancy were investigated. The $\kappa$ parameter as defined in Eq. 1 assumes that there is a linear relationship between $a_{\mathrm{w}}$ and the ratio of solute to solvent i.e. that there is no significant change in the solution non-ideality as function of RH. This assumption was investigated in the sub-saturated regime using the humidograms measured by the HTDMA. An empirical 3 factor parameterisation was used to give an expression for the growth factor as a function of RH (Eq. 17 in Kreidenweis et al., 2005). The water activity is assumed to be equal to the fractional $\mathrm{RH}$ and thus parameterisation was expressed according to Eq. (2) in Allan et al. (2009). A least squares fit was applied to fit the free parameters to the measured data. The empirical fits allow the calculation of the growth factor at any RH within the measured humidograms range. The fits are then used to calculate $\kappa$ as a function of $\mathrm{RH}$ for each humidogram. Figure 9 shows the fitted growth curves (in the top panel) derived from the humidograms which were measured for dry sizes of $43 \mathrm{~nm}, 127 \mathrm{~nm}$ and $211 \mathrm{~nm}$ and the corresponding $\kappa$ values are shown in the lower panel. The $\kappa$ values do not change significantly with RH. There tends to be a small downwards trend in $\kappa(\mathrm{RH})$ for RHs less than 94\% (the highest measurement $\mathrm{RH}$, as indicated by the black dashed line in Fig. 9), though this is within the measurement uncertainty. Above the highest measurement RH the $\kappa$ values follow their existing trajectory until $\sim 98 \%$ RH. Above $98 \%$ the $\kappa$ values appear to increase sharply, however the uncertainty in these point is very large. This points to a limitation of the HTDMA for validating the $\kappa$-model's applicability. Overall below 94\% RH the $\kappa$-model does a good job at capturing the behaviour with a single parameter within the measurement uncertainties. Above $94 \%$ RH it cannot be said how $\kappa$ varies.

If the $\kappa$ parameterisation of the $a_{\mathrm{w}}$ is working well i.e. it remains constant as the $\mathrm{RH}$ approaches $100 \%$ then it could be the formulation of the Kelvin term in the $\kappa$-model that is causing the under-prediction of the $\mathrm{CCN}$ activity. To investigate the possible role of surface effects the time series of the composition (determined as described in Sect. 2.4) was used within ADDEM to match the predicted CCN activity to the measured $\mathrm{CCN}$ activity by varying the surface tension required at the point of activation. To achieve this, a matrix of critical supersaturations were calculated using assumed surface tensions between $50 \mathrm{mN} / \mathrm{m}$ and $80 \mathrm{mN} / \mathrm{m}$, spaced at 


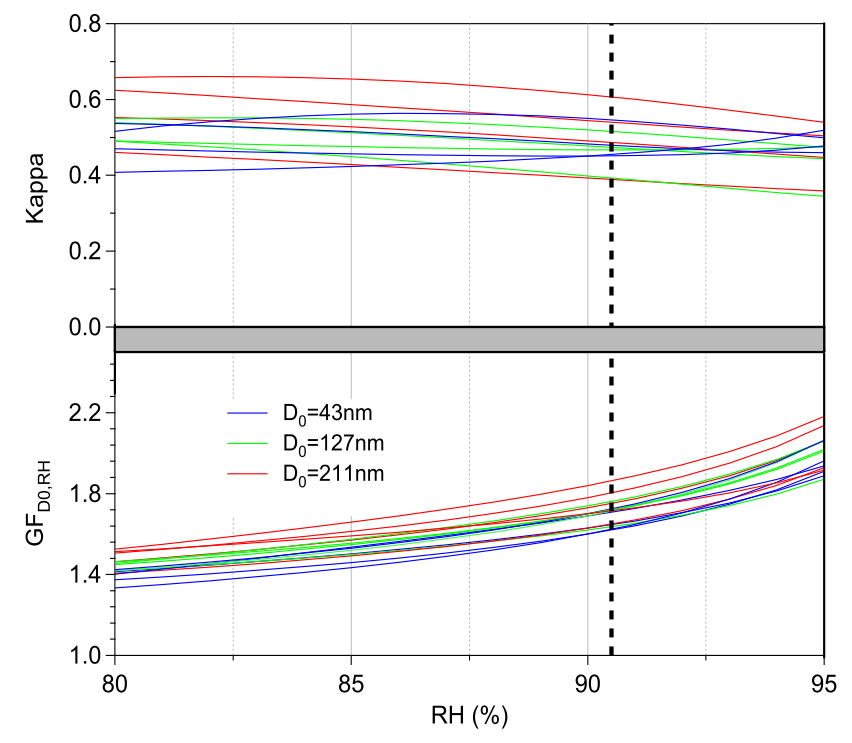

Fig. 9. Measured growth factors and derived $\kappa$ as a function of RH. The top panel shows the $\kappa$ values derived from the humidograms. The bottom panel shows the fitted humidograms for RHs between $80 \%$ and $95 \%$. The dashed line indicates the highest RH the HTDMA measures at.

$0.1 \mathrm{mN} / \mathrm{m}$ intervals. A nonlinear least squared algorithm was then applied to the matrix to find the $S_{\mathrm{c}}$ closest to the measured value to estimate the surface tension at the point of activation required to give agreement between the compositional input and the measured $S_{\mathrm{c}}$. To match the measured and predicted CCN activity it was found that on average surface tensions of $\sim 52 \mathrm{mN} / \mathrm{m}$ for Period 1, $\sim 54 \mathrm{mN} / \mathrm{m}$ for Period 2 and $\sim 60 \mathrm{mN} / \mathrm{m}$ for Period 3 were required. Such reductions in the dilute solutions present at the point of activation are thought to be unphysical and hence surface active behaviour of organic molecules will be unlikely to contribute significantly to the apparent discrepancy.

The limitations of the measurement and analysis techniques must be also considered. Throughout this paper calculations of $\kappa_{\mathrm{HTMDA}}$ and $\kappa_{\mathrm{CCN}}$ have assumed internal mixing. Whilst the growth factors during Periods 1 and 3 tend to fall within a single mode, during Period 2 there is clear external mixing resolvable by the HTDMA. This means particles within an aerosol sample will have a range of $\kappa$ values which will translate into a range of $\mathrm{CCN}$ activities. Therefore the assumption that $50 \%$ activation equates to the $S_{\mathrm{c}}$ may not be consistent with the mixing state at $90 \%$ i.e. when there are 2 externally mixed hygroscopic modes of comparable magnitude the $S_{\mathrm{c}}$ derived from the $D_{0}$ at $50 \%$ activation will fall between the modes. It is difficult to say anything about the $\mathrm{CCN}$ mixing state based on the analysis performed here, without more thorough analysis of the CCN droplet spectra coupled to a model of droplet growth inside the $\mathrm{CCN}$ counter. The $\mathrm{CCN}$ activation spectra (Fig. 6) do not show greater broadening during the African influenced period, which has the most pronounced external mixing at $90 \% \mathrm{RH}$. Inconsistency between the $\mathrm{CCN}$ mixing state and the mixing state at $90 \% \mathrm{RH}$ or smoothing of the mixing state as a result of instrumental or analytical artefacts may cause an inconsistency between the approaches.

\section{Conclusions}

Simultaneous measurements of aerosol CCN activity, hygroscopic growth and composition were made and used to investigate the representation of aerosol water uptake using a single parameter. It was found that the bulk composition was largely consistent with measured hygroscopic growth. The African influenced period saw raised concentrations of refractory aerosol particles affecting the growth factors and as such the AMS was not the best tool to derive the composition for the growth factor predictions. However when $\kappa$ is derived from the HTDMA measurement it should be representative of the full composition. When the ionic composition of the aerosol was well represented the simplified models used to predict the growth factors give good results within the uncertainty of the measured values.

The growth factors at $90 \%$ RH measured by the HTDMA and predicted from the composition were used to derive the hygroscopicity parameter $\kappa$. The $\kappa$-model was used to predict the CCN activity with varying results. The difference between the predicted and measured $\mathrm{CCN}$ number at supersaturations greater than $\sim 0.2 \%$ are typically between $10 \%$ and $20 \%$. There is marked increase in the disagreement at supersaturation lower than $0.2 \%$. The $\mathrm{CCN}$ concentration at these lower supersaturations is an important parameter, as marine stratiform clouds tend to generate peak supersaturations in this range. Uncertainty in $\mathrm{CCN}$ number will propagate into uncertainties in cloud radiative properties. It is difficult to estimate the effect the different $\mathrm{CCN}$ parameterisations presented here would have, without their explicit inclusion in a cloud microphysical model with the appropriate metrological conditions. The sensitivity of marine stratocumulus cloud radiative properties (e.g. cloud albedo and optical depth) to CCN number tends to increase sharply below $\mathrm{CN}$ concentrations of $\sim 1000 \mathrm{~cm}^{-3}$ ( $\mathrm{Lu}$ and Seinfeld, 2005), indicating that effects will be more pronounced for the Marine Period. Hill et al. (2008) used a model to predict the $\mathrm{CCN}$ concentration dependence of indirect aerosol forcing in marine stratocumulus clouds. The most accurate model simulations (2 day averaged, size resolved large-eddy simulation model) suggest a change in radiative forcing in the order of 1 to $3 \mathrm{Wm}^{-2}$ for $20 \%$ changes in CCN number concentration. Facchini et al. (1999) estimate a $20 \%$ increase in cloud droplet number in all stratus clouds would have a global radiative forcing effect of $-1 \mathrm{Wm}^{-2}$. Whilst the impact of the observed discrepancy cannot be precisely stated, it appears that such differences in the CCN number are likely to have a significant impact on cloud properties. 
Acknowledgements. This work was supported by the National Environment Research Council through the Aerosol Characterisation and Modelling in the Marine Environment (ACMME, NE/E011454/1), Integration and synthesis of current research into the formation, evolution and roles of cloud condensation nuclei in the marine environment (NERC SOLAS CCN KT, NE/G000247/1), Characteristics of Organic Microlayer Produced AerosolS (COMPAS, NE/D005175/1) and Reactive Halogens in the Marine Boundary Layer (RHaMBLe, NE/D006570/1), and the $\mathrm{PhD}$ studentships of Nicholas Good (NER/S/A/2005/13221) and Martin Irwin (NER/S/A/2006/14036). ECMWF back trajectories were calculated using the British Atmospheric Data Centre web service (http://badc.nerc.ac.uk/data/ecmwf-trj/).

Edited by: W. T. Sturges

\section{References}

Albrecht, B. A.: Aerosols, Cloud Microphysics, and Fractional Cloudiness, Science, 245, 1227-1230, doi:10.1126/science.245.4923.1227, 1989.

Alfarra, M. R., Paulsen, D., Gysel, M., Garforth, A. A., Dommen, J., Prévôt, A. S. H., Worsnop, D. R., Baltensperger, U., and Coe, H.: A mass spectrometric study of secondary organic aerosols formed from the photooxidation of anthropogenic and biogenic precursors in a reaction chamber, Atmos. Chem. Phys., 6, 52795293, 2006,

http://www.atmos-chem-phys.net/6/5279/2006/.

Allan, J. D., Topping, D. O., Good, N., Irwin, M., Flynn, M., Williams, P. I., Coe, H., Baker, A. R., Martino, M., Niedermeier, N., Wiedensohler, A., Lehmann, S., Müller, K., Herrmann, H., and McFiggans, G.: Composition and properties of atmospheric particles in the eastern Atlantic and impacts on gas phase uptake rates, Atmos. Chem. Phys., 9, 9299-9314, 2009,

http://www.atmos-chem-phys.net/9/9299/2009/.

Andreae, M. O. and Rosenfeld, D.: Aerosol-cloud-precipitation interactions, Part 1, The nature and sources of cloud-active aerosols, Earth-Sci. Rev., 89, 13-41, 2008.

Blanchard, D. and Woodcock, A. H.: Bubble formation and modification in the sea and its meteorologicasl ignificance, Tellus, 9, 145-158, 1957.

Brechtel, F. J. and Kreidenweis, S. M.: Predicting particle critical supersaturation from hygroscopic growth measurements in the humidified TDMA, Part I: Theory and sensitivity studies, J. Atmos. Sci., 57, 1854-1871, 2000.

Canagaratna, M. R., Jayne, J. T., Jimenez, J. L., Allan, J. D., Alfarra, M. R., Zhang, Q., Onasch, T. B., Drewnick, F., Coe, H., Middlebrook, A., Delia, A., Williams, L. R., Trimborn, A. M., Northway, M. J., DeCarlo, P. F., Kolb, C. E., Davidovits, P., and Worsnop, D. R.: Chemical and microphysical characterization of ambient aerosols with the aerodyne aerosol mass spectrometer, Mass Spectrom. Rev., 26, 185-222, 2007.

Charlson, R. J., Langner, J., Rodhe, H., Leovy, C. B., and Warren, S. G.: Perturbation of the Northern-Hemisphere Radiative Balance by Backscattering from Anthropogenic Sulfate Aerosols, Tellus A, 43, 152-163, 1991.
Charlson, R. J., Schwartz, S. E., Hales, J. M., Cess, R. D., Coakley, J. A., Hansen, J. E., and Hofmann, D. J.: Climate Forcing by Anthropogenic Aerosols, Science, 255, 423-430, doi:10.1126/science.255.5043.423, 1992.

Clegg, S. L., Brimblecombe, P., and Wexler, A. S.: Thermodynamic model of the system $\mathrm{H}^{+}-\mathrm{NH}^{+4}-\mathrm{Na}^{+}-\mathrm{SO}_{2}^{-4}-\mathrm{NH}_{3}-\mathrm{Cl}-\mathrm{H}_{2} \mathrm{O}$ at 298.15 K, J. Phys. Chem., 102, 2155-2171, 1998.

Cubison, M. J., Coe, H., and Gysel, M.: A modified hygroscopic tandem DMA and a data retrieval method based on optimal estimation, J. Aerosol Sci., 36, 846-865, doi:10.1016/j.jaerosci.2004.11.009, 2005.

DeCarlo, P. F., Dunlea, E. J., Kimmel, J. R., Aiken, A. C., Sueper, D., Crounse, J., Wennberg, P. O., Emmons, L., Shinozuka, Y., Clarke, A., Zhou, J., Tomlinson, J., Collins, D. R., Knapp, D., Weinheimer, A. J., Montzka, D. D., Campos, T., and Jimenez, J. L.: Fast airborne aerosol size and chemistry measurements above Mexico City and Central Mexico during the MILAGRO campaign, Atmos. Chem. Phys., 8, 4027-4048, 2008, http://www.atmos-chem-phys.net/8/4027/2008/.

Demokritou, P., Lee, S. J., Ferguson, S. T., and Koutrakis, P.: A compact multistage (cascade) impactor for the characterization of atmospheric' aerosols, J. Aerosol. Sci., 35, 281-299, 2004.

Dick, W. D., Saxena, P., and McMurry, P. H.: Estimation of water uptake by organic compounds in submicron aerosols measured during the Southeastern Aerosol and Visibility Study, J. Geophys. Res.-Atmos., 105, 1471-1479, 2000.

Dinar, E., Mentel, T. F., and Rudich, Y.: The density of humic acids and humic like substances (HULIS) from fresh and aged wood burning and pollution aerosol particles, Atmos. Chem. Phys., 6, 5213-5224, 2006, http://www.atmos-chem-phys.net/6/5213/2006/.

Facchini, M. C., Mircea, M., Fuzzi, S., and Charlson, R. J.: Cloud albedo enhancement by surface-active organic solutes in growing droplets, Nature, 401, 257-259, 1999.

Fitzgerald, J. W.: Marine Aerosols - a Review, Atmos. Environ. A-Gen., 25, 533-545, 1991.

Forster, P., Ramaswamy, P. V., Artaxo, P., Berntsen, T., Betts, R., Fahey, D. W., Haywood, J., Lean, J., Lowe, D. C., Myhre, G., Nganga, J., Prinn, R., Raga, G., Schulz, M., and Van Dorland, R.: Changes in Atmospheric Constituents and in Radiative Forcing, in: Climate Change 2007: The Physical Science Basis, Contribution of Working Group I to the Fourth Assessment Report of the Intergovernmental Panel on Climate Change, Cambridge University Press, 2007.

Good, N., Coe, H., and McFiggans, G.: Instrumentational operation and analytical methodology for the reconciliation of aerosol water uptake under sub- and supersaturated conditions, Atmos. Meas. Tech. Discuss., 3, 359-403, 2010, http://www.atmos-meas-tech-discuss.net/3/359/2010/.

Gysel, M., Crosier, J., Topping, D. O., Whitehead, J. D., Bower, K. N., Cubison, M. J., Williams, P. I., Flynn, M. J., McFiggans, G. B., and Coe, H.: Closure study between chemical composition and hygroscopic growth of aerosol particles during TORCH2, Atmos. Chem. Phys., 7, 6131-6144, 2007, http://www.atmos-chem-phys.net/7/6131/2007/.

Gysel, M., McFiggans, G., and Coe, H.: Inversion of tandem differential mobility analyser (TDMA) measurements, J. Aerosol Sci. 40, 134-151, doi:10.1016/j.jaerosci.2008.07.013, 2009. 
Harrison, E. F., Minnis, P., Barkstrom, B. R., Ramanathan, V., Cess, R. D., and Gibson, G. G.: Seasonal-Variation of Cloud Radiative Forcing Derived from the Earth Radiation Budget Experiment, J. Geophys. Res.-Atmos., 95, 18687-18703, 1990.

Hartmann, D. L., Ockertbell, M. E., and Michelsen, M. L.: The Effect of Cloud Type on Earths Energy-Balance - Global Analysis, J. Climate, 5, 1281-1304, 1992.

Hill, A. A., Dobbie, S., and Yin, Y.: The impact of aerosols on nonprecipitating marine stratocumulus, I: Model description and prediction of the indirect effect, Q. J. Roy. Meteor. Soc., 134, 11431154, 2008.

Hoppel, W. A., Frick, G. M., and Fitzgerald, J. W.: Deducing droplet concentration and supersaturation in marine boundary layer clouds from surface aerosol measurements, J. Geophy. Res.-Atmos., 101, 26553-26565, 1996.

Hudson, J. G. and Svensson, G.: Cloud Microphysical Relationships in California Marine Stratus, J. Appl. Meteorol., 34, 26552666, 1995.

Jacobson, M. Z.: Strong radiative heating due to the mixing state of black carbon in atmospheric aerosols, Nature, 409, 695-697, doi:10.1038/35055518, 2001.

Klein, S. A. and Hartmann, D. L.: The Seasonal Cycle of Low Stratiform Clouds, J. Climate, 6, 1587-1606, 1993.

Köhler, H.: The Nucleus In and the Growth of Hygroscopic Droplets, T. Faraday Soc., 32, 1152-1161, 1936.

Kreidenweis, S. M., Koehler, K., DeMott, P. J., Prenni, A. J., Carrico, C., and Ervens, B.: Water activity and activation diameters from hygroscopicity data - Part I: Theory and application to inorganic salts, Atmos. Chem. Phys., 5, 1357-1370, 2005, http://www.atmos-chem-phys.net/5/1357/2005/.

Kreidenweis, S. M., Petters, M. D., and DeMott, P. J.: Singleparameter estimates of aerosol water content, Environ. Res. Lett., 3(3), 035002, doi:10.1088/1748-9326/3/3/035002, 2008.

Lee, J. D., McFiggans, G., Allan, J. D., Baker, A. R., Ball, S. M., Benton, A. K., Carpenter, L. J., Commane, R., Finley, B. D., Evans, M., Fuentes, E., Furneaux, K., Goddard, A., Good, N., Hamilton, J. F., Heard, D. E., Herrmann, H., Hollingsworth, A., Hopkins, J. R., Ingham, T., Irwin, M., Jones, C. E., Jones, R. L., Keene, W. C., Lawler, M. J., Lehmann, S., Lewis, A. C., Long, M. S., Mahajan, A., Methven, J., Moller, S. J., Müller, K., Müller, T., Niedermeier, N., O'Doherty, S., Oetjen, H., Plane, J. M. C., Pszenny, A. A. P., Read, K. A., Saiz-Lopez, A., Saltzman, E. S., Sander, R., von Glasow, R., Whalley, L., Wiedensohler, A., and Young, D.: Reactive Halogens in the Marine Boundary Layer (RHaMBLe): the tropical North Atlantic experiments, Atmos. Chem. Phys., 10, 1031-1055, 2010, http://www.atmos-chem-phys.net/10/1031/2010/.

Li, Z. D., Williams, A. L., and Rood, M. J.: Influence of soluble surfactant properties on the activation of aerosol particles containing inorganic solute, J. Atmos. Sci., 55, 1859-1866, 1998.

Liu, B. Y. H., Pui, D. Y. H., Whitby, K. T., Kittelson, D. B., Kousaka, Y., and McKenzie, R. L.: Aerosol Mobility Chromatograph - New Detector for Sulfuric-Acid Aerosols, Atmos. Environ., 12, 99-104, 1978.

Lu, M. L. and Seinfeld, J. H.: Study of the aerosol indirect effect by large-eddy simulation of marine stratocumulus, J. Atmos. Sci., 62, 3909-3932, 2005.
Martin, G. M., Johnson, D. W., and Spice, A.: The Measurement and Parameterization of Effective Radius of Droplets in Warm Stratocumulus Clouds, J. Atmos. Sci., 51, 1823-1842, 1994.

McFiggans, G., Artaxo, P., Baltensperger, U., Coe, H., Facchini, M. C., Feingold, G., Fuzzi, S., Gysel, M., Laaksonen, A., Lohmann, U., Mentel, T. F., Murphy, D. M., O’Dowd, C. D., Snider, J. R., and Weingartner, E.: The effect of physical and chemical aerosol properties on warm cloud droplet activation, Atmos. Chem. Phys., 6, 2593-2649, 2006,

http://www.atmos-chem-phys.net/6/2593/2006/.

McMurry, P. H. and Stolzenburg, M. R.: On the Sensitivity of Particle-Size to Relative-Humidity for Los-Angeles Aerosols, Atmos. Environ., 23, 497-507, 1989.

O'Dowd, C. D. and Smith, M. H.: Physicochemical Properties of Aerosols Over the Northeast Atlantic: Evidence for Wind-SpeedRelated Submicron Sea-Salt Aerosol Production, J. Geophys. Res., 98, 145-158, 1993.

Petters, M. D. and Kreidenweis, S. M.: A single parameter representation of hygroscopic growth and cloud condensation nucleus activity, Atmos. Chem. Phys., 7, 1961-1971, 2007, http://www.atmos-chem-phys.net/7/1961/2007/.

Prenni, A. J., Petters, M. D., Kreidenweis, S. M., DeMott, P. J., and Ziemann, P. J.: Cloud droplet activation of secondary organic aerosol, J. Geophys. Res.-Atmos., 112, D10223, doi:10.1029/2006JD007963, 2007.

Ramanathan, V., Cess, R. D., Harrison, E. F., Minnis, P., Barkstrom, B. R., Ahmad, E., and Hartmann, D.: Cloud-Radiative Forcing and Climate - Results from the Earth Radiation Budget Experiment, Science, 243, 57-63, doi:10.1126/science.243.4887.57, 1989.

Roberts, G. C. and Nenes, A.: A continuous-flow streamwise thermal-gradient $\mathrm{CCN}$ chamber for atmospheric measurements, Aerosol Sci. Tech., 39, 206-221, 2005.

Rose, D., Gunthe, S. S., Mikhailov, E., Frank, G. P., Dusek, U., Andreae, M. O., and Pöschl, U.: Calibration and measurement uncertainties of a continuous-flow cloud condensation nuclei counter (DMT-CCNC): CCN activation of ammonium sulfate and sodium chloride aerosol particles in theory and experiment, Atmos. Chem. Phys., 8, 1153-1179, 2008, http://www.atmos-chem-phys.net/8/1153/2008/.

Shilling, J. E., King, S. M., Mochida, M., and Martin, S. T.: Mass spectral evidence that small changes in composition caused by oxidative aging processes alter aerosol CCN properties, J. Phys. Chem., 111, 3358-3368, 2007.

Sorjamaa, R., Svenningsson, B., Raatikainen, T., Henning, S., Bilde, M., and Laaksonen, A.: The role of surfactants in Khler theory reconsidered, Atmos. Chem. Phys., 4, 2107-2117, 2004, http://www.atmos-chem-phys.net/4/2107/2004/.

Stokes, R. H. and Robinson, R. A.: Interactions in aquous nonelectrolyte solutions I. Solute-solvent equilibria, J. Phys. Chem., 70, 2126-2130, 1966.

Svenningsson, I. B., Hansson, H. C., Wiedensohler, A., Ogren, J. A., Noone, K. J., and Hallberg, A.: Hygroscopic Growth of Aerosol-Particles in the Po Valley, Tellus B, 44, 556-569, 1992.

Swietlicki, E., Zhou, J. C., Berg, O. H., Martinsson, B. G., Frank, G., Cederfelt, S. I., Dusek, U., Berner, A., Birmili, W., Wiedensohler, A., Yuskiewicz, B., and Bower, K. N.: A closure study of sub-micrometer aerosol particle hygroscopic behaviour, Atmos. Res., 50, 205-240, 1999. 
Tegen, I. and Lacis, A. A.: Modeling of particle size distribution and its influence on the radiative properties of mineral dust aerosol, J. Geophys. Res., 101, 19237-19244, 1996.

Tegen, I., Lacis, A. A., and Fung, I.: The influence on climate forcing of mineral aerosols from disturbed soils, Nature, 380, 419422, doi:10.1038/380419a0, 1996.

Topping, D. O., McFiggans, G. B., and Coe, H.: A curved multicomponent aerosol hygroscopicity model framework: Part 1 - Inorganic compounds, Atmos. Chem. Phys., 5, 1205-1222, 2005a, http://www.atmos-chem-phys.net/5/1205/2005/.

Topping, D. O., McFiggans, G. B., and Coe, H.: A curved multicomponent aerosol hygroscopicity model framework: Part 2 Including organic compounds, Atmos. Chem. Phys., 5, 1223$1242,2005 b$, http://www.atmos-chem-phys.net/5/1223/2005/.

Topping, D. O., McFiggans, G. B., Kiss, G., Varga, Z., Facchini, M. C., Decesari, S., and Mircea, M.: Surface tensions of multicomponent mixed inorganic/organic aqueous systems of atmospheric significance: measurements, model predictions and importance for cloud activation predictions, Atmos. Chem. Phys., 7, 2371-2398, 2007,

http://www.atmos-chem-phys.net/7/2371/2007/.
Twomey, S.: Pollution and Planetary Albedo, Atmos. Environ., 8, 1251-1256, 1974

Weingartner, E., Burtscher, H., and Baltensperger, U.: Hygroscopic properties of carbon and diesel soot particles, Atmos. Environ., 31, 2311-2327, doi:10.1016/S1352-2310(97)00023-X, 1997.

Wiedensohler, A.: An Approximation of the Bipolar ChargeDistribution for Particles in the Sub-Micron Size Range, J. Aerosol Sci., 19, 387-389, doi:10.1016/0021-8502(88)90278-9, 1988.

Williams, P. I., McFiggans, G., and Gallagher, M. W.: Latitudinal aerosol size distribution variation in the Eastern Atlantic Ocean measured aboard the FS-Polarstern, Atmos. Chem. Phys., 7, 2563-2573, 2007, http://www.atmos-chem-phys.net/7/2563/2007/.

Zaveri, R. A., Easter, R. C., and Wexler, A. S.: A new method for multicomponent activity coefficients of electrolytes in aqueous atmospheric aerosols, J. Geophys. Res.-Atmos., 110, D02201, doi:10.1029/2004JD004681, 2005. 